EPV221/\#599 IMPLEMENTATION AND FEASIBILITY OF PROPHYLACTIC BILATERAL SALPINGECTOMY AT BENIGN, MINIMALLY INVASIVE (VAGINAL AND LAPAROSCOPIC) HYSTERECTOMY IN STYRIA (AUSTRIA)

${ }^{1} \mathrm{C}$ Hütter, ${ }^{2} \mathrm{~K}$ Simon, ${ }^{3} \mathrm{M}$ Kratky, ${ }^{4} \mathrm{C}$ Mutz-Eckhart, ${ }^{5} \mathrm{~S}$ Klammer, ${ }^{6} \mathrm{C}$ Bermann, ${ }^{7} \mathrm{~A}$ Huber ${ }^{8} \mathrm{~V}$ Lessiak, ${ }^{5} \mathrm{M}$ Blatt-Gunegger, ${ }^{1} \mathrm{~K}$ Tamussino*. ${ }^{1}$ Medical University of Graz, Obstetrics and Gynecology, Graz, Austria; ${ }^{2}$ LKH Leoben, Obstetrics and Gynecology, Leoben, Austria; ${ }^{3}$ LKH Deutschlandsberg, Obgyn, Deutschlandsberg, Austria; ${ }^{4}$ LKH Judenburg, Obgyn, Judenburg, Austria; ${ }^{5}$ LKH Rottenmann, Obgyn, Rottenmann, Austria; ${ }^{6}$ LKH Hartberg, Obgyn, Hartberg, Austria; 'LKH Feldbach, Obgyn, Feldbach, Austria; ${ }^{8} \mathrm{KH}$ der Barmberzigen Brüder, Gyn, Graz, Austria

\subsection{6/ijgc-2021-IGCS.292}

Objectives Numerous societies, including the Austrian Society of Obstetrics \& Gynecology (OEGGG) in 2015, have recommended prophylactic bilateral salpingectomy (PBS) at the time of benign gynecologic surgery with the intent of ovarian cancer risk reduction. We evaluated implementation and feasibility of PBS at benign, minimally invasive hysterectomy in public hospitals in the Austrian province of Styria in 2014 vs. 2018 (before and after the official recommendation in 2015).

Methods We reviewed surgical consent forms and operative notes of patients undergoing vaginal or laparoscopic hysterectomy for benign indications in Styria in 2014 and 2018. Ethics approval was obtained.

Results 1256 benign, minimally invasive hysterectomies were identified (580 in 2014, 676 in 2018). 68\% of patients were consented for PBS in 2014 and 94\% in 2018 ( $\mathrm{P}<0.05)$. The PBS rate in consented patients was $88 \%$ in 2014 and $83 \%$ in 2018 (n.s.). In 2018 PBS was completed more often at laparoscopic than at vaginal hysterectomy $(95 \%$ vs. $74 \%, \mathrm{P}<0.05)$. Age and parity were the major influencing factors for success of PBS.

Conclusions PBS at minimally invasive hysterectomy was widely performed in Styria even before the official recommendation in 2015, and increased thereafter to $83 \%$ overall in 2018. PBS was accomplished somewhat more often at laparoscopic than at vaginal hysterectomy.

\section{EPV222/\#603 RADIOLOGICAL RESPONSE TO NEOADJUVANT CHEMOTHERAPY AS INDICATOR OF OPTIMAL CYTOREDUCTION IN ADVANCED OVARIAN CANCER}

\footnotetext{
1,25 Maricic*, 1,2A Mandic, 1,3 N Prvulovic Bunovic, 'S Stojanovic, ' I Stojic, ${ }^{1,4} \mathrm{~N}$ Stanulovic. ${ }^{1}$ University of Novi Sad, Faculty of Medicine, Novi Sad, Serbia; ${ }^{2}$ Oncology Insitute of Vojvodina, Gynecology Department, Sremska Kamenica, Serbia; ${ }^{3}$ Oncology Insitute of Vojvodina, Radiology Department, Sremska Kamenica, Serbia; ${ }^{4}$ Oncology Insitute of Vojvodina, Pathology Department, Sremska Kamenica, Serbia
}

\subsection{6/ijgc-2021-IGCS.293}

Objectives The extent of tumor cytoreduction (residual tumor volume) is the most important prognostic factor in advanced ovarian cancer (AOC). Neoadjuvant chemotherapy (NACT) followed by interval debulking surgery (IDS) is an option in cases where optimal cytoreduction is not possible in upfront surgery. Despite that NACT did not raise the survival rate, it still showed increased cytoreduction rate, decreased surgical morbidity and good progression-free interval. The purpose of this study is to determine the role of imaging in the prediction of the extent of cytoreduction after NACT.
Methods The 37 patients with AOC were included in the study. They were operated in our center after the administration of NACT. Evaluation of the response to NACT was done with CT/MRI after 3-4 cycles of NACT.

Results NACT was administered in 3 or 4 cycles of Paclitaxel/ Carboplatin protocol. Patients were diagnosed in FIGO stage III $(29 ; 78,4 \%)$ or IV $(8 ; 21,6 \%)$. Cytological $(26 ; 70,3 \%)$ or histopathological $(9 ; 29,7 \%)$ confirmation of malignancy was done prior chemotherapy. According to imaging, 32 subjects $(86,5 \%)$ achieved a partial response (PR) to chemotherapy, 4 of them $(11,8 \%)$ obtained complete response (CR) and one retained stable disease $(2,7 \%)$. Out of those subjects with PR, $19(59,4 \%)$ had optimal debulking, while $13(40,6 \%)$ had a suboptimal debulking procedure. All 4 of the patients with CR had complete debulking, while one with SD had suboptimal debulking.

Conclusions Imaging evaluation of response to NACT is a valid method to assess surgical resectability and select patients appropriate for complete cytoreduction.

\section{EPV223/\#608 THE DIAGNOSTIC ACCURACY OF HUMAN EPIDIDYMIS PROTEIN 4 (HE4) FOR DISCRIMINATING BETWEEN BENIGN AND MALIGNANT PELVIC MASSES: A SYSTEMATIC REVIEW AND META-ANALYSIS}

${ }^{1} \mathrm{P}$ Lof ${ }^{*},{ }^{2} \mathrm{M}$ Olsen, ${ }^{1} \mathrm{~A}$ Stiekema, ${ }^{3} \mathrm{D}$ Van Den Broek, ${ }^{4} \mathrm{E}$ Wilthagen, ${ }^{2} \mathrm{P}$ Bossuyt, ${ }^{1} \mathrm{C}$ Lok. ${ }^{1}$ Netherlands Cancer Institute, Gynecology, Amsterdam, Netherlands; ${ }^{2}$ Amsterdam University Medical Center, Clinical Epidemiology, Biostatistics and Bioinformatics, Amsterdam, Netherlands; ${ }^{3}$ Netherlands Cancer Institute, Laboratory Medicine, Amsterdam, Netherlands; ${ }^{4}$ Netherlands Cancer Institute, Scientific Information Service, Amsterdam, Netherlands

\subsection{6/ijgc-2021-IGCS.294}

Objectives There is an unmet need to improve accurate detection of malignancy in patients with pelvic masses. Our objective was to obtain summary estimates of HE4 accuracy for diagnosing malignancy and to compare performance with CA125, in different clinical settings.

Methods We searched PubMed, Ovid and Scopus using terms for 'pelvic masses' and 'HE4', to identify studies that evaluated HE4 for diagnosing malignant ovarian masses. Screening, data extraction and quality assessment were done independently by two authors. We performed meta-analysis of HE4 and CA125 accuracies using a random-effects bivariate logit-normal model.

Results In the 17 eligible studies, OC prevalence ranged from $15 \%$ to $71 \%$. All studies seemed to have recruited patients in specialized settings. A meta-analysis of $7 \mathrm{HE} 4$-studies resulted in a mean sensitivity and specificity $(95 \%$ CI) of $79.4 \%$ (74.1\%-83.8\%) and $84.1 \%$ (79.6\%-87.8\%), for cut-off values of $67-72 \mathrm{pmol} / \mathrm{L}$. Based on 8 studies, the mean sensitivity and specificity of CA125 was $81.4 \% \quad(74.6 \%-86.2 \%)$ and $56.8 \%(47.9 \%-65.4 \%)$, respectively, at a cut-off of $35 \mathrm{U} / \mathrm{mL}$. Given a $40 \%$ OC prevalence, the positive predictive value (PPV) for HE4 was 76.9\% (71.9\%-81.2\%) versus $55.6 \%$ (50.2\%-60.9\%) for CA125. At a 15\% prevalence, the negative predictive value (NPV) was 95.8\% (95\% CI: 94.4\%-96.7\%) and 94.4\% (95\% CI: 92.3\%-96.0), respectively.

Conclusions HE4 had higher specificity and similar sensitivity compared to CA125. At high prevalence in specialized settings, PPV is higher for HE4. At low prevalence in general settings, NPV of HE4 is similar to CA125. Prevalence and 
setting are important variables that should always be reported in biomarker research.

\section{EPV224/\#620 RADIOTHERAPY FOR PLATINUM-RESISTANT (PR) OVARIAN CANCER: SHOULD THIS BE RECONSIDERED AS A STANDARD TREATMENT OPTION?}

L Kviat*, S Banerjee, A Taylor, A George. The Royal Marsden NHS Foundation Trust, Gynaecology Unit, London, UK

\subsection{6/ijgc-2021-IGCS.295}

Objectives Radiotherapy for recurrent ovarian cancer has traditionally had a limited role due to toxicity, but recent advances enable more targeted treatments. The aims were to evaluate patterns of disease in PR ovarian cancer and investigate feasibility of radiotherapy to treat abdomino-pelvic disease.

Methods Gynaecology oncology clinic lists were retrospectively reviewed to identify 50 patients with PR ovarian cancer. Tumour location on imaging at time-point of platinum-resistance was mapped with cumulative incidences by quadrant. Three groups were defined: RT_Feasible - pelvis and lymph nodes; RT_Not Feasible -liver parenchymal metastases, gross ascites, bowel obstruction; RT_Uncertain including peritoneal disease. A dosimetric study was undertaken on ten consecutive RT-Uncertain patients producing IMRT plans delivering 30Gy/ 10 fractions with pre-defined normal structure dose constraints.

Results From 399 patients attending Nov 2019-Feb 2020, 88 (22\%) had PR disease, with 63\% confined to abdomen-pelvis. Disease was typically multi-focal with involvement of 2 or more quadrants in $84 \%$, and $88 \%$ having upper abdominal disease. Group allocation was RT_Feasible 22\%, RT_NotFeasible18\% and RT_Uncertain 60\%. There was median 5 (range 2-9) separate tumour volumes with total volume median 13.6 $\mathrm{cm}^{3}$ (range $6.5-400.3 \mathrm{~cm}^{3}$ ) resulting in planning target volumes median $458.6 \mathrm{~cm}^{3}$ (243-3077). IMRT plans encompassed tumour volumes while meeting all normal structure tolerances in $50 \%$ cases, with all plans failing for planning volumes $>1000 \mathrm{~cm}^{3}$.

Conclusions PR ovarian cancer is often widespread, but radiotherapy was feasible for $52 \%$ cases with abdomino-pelvic disease. RT could be integrated into novel treatment strategies for these patients who currently have limited options.

\section{EPV225/\#623 SAFETY OF A NEW CLOSED CO2 PERITONEAL RECIRCULATION SYSTEM (PRS) HYPERTHERMIC INTRAPERIONEAL CHEMOTHERAPY (HIPEC) AFTER INTERVAL DEBULKING SURGERY (IDS) IN ADVANCED OVARIAN CANCER (AOC) PATIENTS}

${ }^{1} \mathrm{~F}$ Murgia, ${ }^{1} \mathrm{~V}$ Carone, ${ }^{1} \mathrm{~L}$ Leone, ${ }^{2} \mathrm{~L}$ Laera, ${ }^{3} \mathrm{~F}$ Lombardi, ${ }^{3} \mathrm{I}$ Brunetti, ${ }^{2} \mathrm{G}$ Surico, ${ }^{1,4} \mathrm{~F}$ Legge* ${ }^{1}$ F. Miulli' General Regional Hospital, Gynecologic Oncology Unit, Acquaviva Delle Fonti, Italy; ${ }^{2}$ General Regional Hospital "F. Miulli", Medical Oncology, Acquaviva delle Fonti, Italy; ${ }^{3}$ General Regional Hospital "F. Miulli", Department of Anesthesiology and Intensive Care Medicine, Acquaviva delle Fonti, Italy; ${ }^{4}$ General Regional Hospital 'F. Miulli', Obstetrics and Gynecology, Acquaviva delle Fonti, Italy

\subsection{6/ijgc-2021-IGCS.296}

Objectives The avaliability of new devices aimed at improving fluid distribution with a CO2 Peritoneal Recirculation System (PRS-1.0 Combat) may be useful to further improve the clinical benefit recently showed by hypertermic intraperitoneal chemotherapy (HIPEC) after interval debulking surgery (IDS) in advanced ovarian cancer (AOC) patients. This study aimed at assessing the feasibility and perioperative outcomes of the CO2 PRS HIPEC after IDS.

Methods Over the study period 24 patients were prospectively enrolled. Patients underwent 3 neoadjuvant cycles of carboplatin AUC5 + paclitaxel $175 \mathrm{mg} / \mathrm{m} 2$ and IDS with absent residual disease. Sodium thiosulfate $(9 \mathrm{~g} / \mathrm{m} 2)$ was administered before CO2 PRS HIPEC with cisplatin $(75 \mathrm{mg} / \mathrm{m} 2$, temperature $42^{\circ} \mathrm{C}$, for 60 minutes).

Results Almost one third of patients (37,5\%) underwent ultraradical surgery with $12.5 \%$ bowel resections. Median blood loss was 500 (100-1200) $\mathrm{mL}$ and mean operative time 407.5 minutes. Median (range) intensive care unit stay and time-todischarge were $0(0-10)$ and 6 (4-17) days, respectively. We registered 3/24 (12.5\%) early serious adverse events including one acute respiratory failure and two acute kidney injuries (only one of these retained a mild chronic renal failure); one patient was readmitted within 30 days after discharge because of a dehiscence of the vaginal vault. No late adverse events were reported. Median time-to-chemotherapy was 33 days (range 22- 51).

Conclusions The CO2 PRS may improve the safety profile of HIPEC in the setting of IDS for AOC patients probably because of the more tailored drug distribution.

\section{EPV226/\#634 HYPERTHERMIC INTRAPERITONEAL CHEMOTHERAPY WITH CO2 RECIRCULATION SYSTEM (PRS) AFTER INTERVAL DEBULKING SURGERY IN ADVANCED OVARIAN CANCER (AOC): PRELIMINARY EFFICACY RESULTS FROM A PHASE II STUDY}

\begin{abstract}
${ }^{1} \mathrm{~F}$ Murgia, ${ }^{1} \mathrm{~V}$ Carone, ${ }^{1} \mathrm{~L}$ Leone, ${ }^{1} \mathrm{~V}$ Caroli Casavola, ${ }^{2} \mathrm{~A}$ Cristofano, ${ }^{1} \mathrm{~A}$ Milano ${ }^{3} \mathrm{~V}$ Delmonte, ${ }^{2} \mathrm{G}$ Surico, ${ }^{1} \mathrm{~F}$ Legge*. ${ }^{1} \mathrm{~F}$. Miulli' General Regional Hospital, Gynecologic Oncology Unit, Acquaviva Delle Fonti, Italy; ${ }^{2}$ General Regional Hospital "F. Miulli", Medical Oncology, Acquaviva delle Fonti, Italy; ${ }^{3}$ General Regional Hospital "F. Miulli", Department of Anesthesiology and Intensive Care Medicine, Acquaviva delle Fonti, Italy
\end{abstract}

\subsection{6/ijgc-2021-IGCS.297}

Objectives The addition of HIPEC to IDS in AOC has recently showed advantages in prolonging both disease-free and overall survival in AOC patients responding to neoadjuvant chemotherapy. We investigated the pattern of recurrence in a preliminary series of AOC patients treated by HIPEC with a new CO2 PRS after IDS.

Methods Twenty patients were prospectively enrolled during the study period. All patients underwent 3 cycles of neoadjuvant chemotherapy with carboplatin AUC5 + paclitaxel 175 $\mathrm{mg} / \mathrm{m} 2$ and achieved complete cytoreduction at the time of IDS. HIPEC with cisplatin $\left(75 \mathrm{mg} / \mathrm{m} 2\right.$, temperature $42^{\circ} \mathrm{C}$, for 60 minutes) was administered with a closed CO2 PRS.

Results Seven out of twenty (35\%) patients underwent ultraradical surgical procedures and $3(15 \%)$ bowel resection. After a median follow-up of 21 months (range 7-28) we registered 9 recurrences with a median time-to-recurrence of 9 months (range 5-21). Interestingly $7 / 9$ (77.8\%) recurrences were nodal while only one patient had peritoneal relapse (5\%) and one more recurred with pleural disease. Only 2 patients died from relapsed disease.

Conclusions Our preliminary efficacy data showed that peritoneal recurrence in AOC may be potentially reduced by the 